\title{
Construction of a survey to assess workload and fatigue among AMT operators in Mexico
}

\author{
Juan Luis Hernández Arellano, ${ }^{\mathrm{a}, 1}$, Gabriel Ibarra Mejía ${ }^{\mathrm{a}}$, J Nieves Serratos Pérez ${ }^{\mathrm{b}}$, Jorge Luis García \\ Alcaraz ${ }^{\mathrm{a}}$, María Julia Brunette ${ }^{\mathrm{c}}$ \\ ${ }^{a}$ Instituto de Ingeniería y Tecnología.Universidad Autónoma de Ciudad Juárez, Av. Del Charro 610. C.P. 32310 \\ Ciudad Juárez Chihuahua, México. \\ ${ }^{b}$ Departamento de Ciencias Aplicadas al Trabajo. Universidad de Guanajuato. Av. Eugenio Garza Sada $N^{\circ} 572$. \\ C. P. 37150. León, Gto. \\ ${ }^{\mathrm{c}}$ Work Environment Department. University of Massachusetts Lowell. One University Avenue. Lowell, Ma.
}

\begin{abstract}
Operators of machinery classified as Advanced Manufacturing Technology (AMT) are exposed to high levels of workload and fatigue. However, only few studies have been conducted on this topic in Hispanic-American countries workers. Several instruments be used to assess workload and fatigue; however, only few of them have been adapted to Spanish language. This paper reports on the development and validity testing of a survey instrument in Spanish, aiming to subjectively assess workload and fatigue among AMT operators in Mexico. Method: After an exhaustive literature review in search of already available measurement instruments, they were adapted for content and later translated into Spanish; a pilot test was conducted to evaluate validity and reliability; afterwards appropriate modifications were made to the testing instruments. Final version of the instrument was applied to a group of 121 operators of CNC lathes. Reliability was analyzed using KMO and Cronbach alpha indices. Results: For the assessment of workload, both NASA-TLX and ISTAS 21 methods were incorporated to the survey instrument. As for fatigue assessment tools, these were SOFI-S, FAS and OFER questionnaires. Results show KMO value and Cronbach alpha above 0.6.Conclusions. The survey instrument as designed, allows the collection of reliable and valid data regarding workload and fatigue among AMT operators in Mexico.
\end{abstract}

Keywords: fatigue, workload, assessment, reliability, AMT

\section{Introduction}

\subsection{Workload}

The workload is a construct intrinsically complex and multifaceted [9] usually defined as the portion of resources spent to performing a particular activity, for example, the maximum capacity of performance [24]. Another definition is the cost incurred by an individual given their skills while performing a particular level of performance on a task with specific demands [33].

Methods for assessing subjective mental workload have shown high sensitivity, minimum implementation requirements, very good acceptance by workers, and adequate levels of validity in contrast, physiolog- ical indices and measures of job performance, have shown serious difficulties to be measured in the workplace $[2,1]$.

Some of the most widely used subjective methods for assessing mental workload are: Laboratory of Labour Economics and Sociology (LEST) [9], Modified Copper-Harper (CHM) [40], Overall Workload Scale (OWS) [25], National Aeronautics and Space Administration Task Load Index (NASA-TLX) [33], Subjective Workload Assessment Technique (SWAT) [11], Multivariate Workload Evaluation (MWE) [34], Overall Workload Level (OWL) [15], Institute of Work, Environment and Health (ISTAS 21) [35] Subjective Mental Workload Scale (SCAM) [12].

\footnotetext{
${ }^{1}$ Corresponding author: luis.hernandez@uacj.mx
} 
Methods mentioned above, there are only Spanish language versions of the LEST, Copper-Harper Modified, NASA-TLX and SCAM. In the case of Latin America and specifically in Mexico, the literature review did not reveal any previously used or developed method for subjective assessment of mental workload

\subsection{Fatigue}

Fatigue is commonly used to indicate a physiological status, but some psychologists agree that this should be used only to define a subjective experience that further limits the performance of a task [23].

Some of the most widely used subjective methods for assessing work-related fatigue are: FatigueRelated Symptoms Questionnaire (F-RSQ) [16], Borg Scale [10], Swedish Occupational Fatigue Inventory (SOFI) [5], Fatigue Assessment Scale (FAS) [14], Occupational Fatigue Exhaustion Recovery (OFER) [28], the Spanish version of the SOFI (SOFIS)[18],Occupational Fatigue Exhaustion Recovery (OFER) [28],Fatigue Scale Energy Point Estimates (FEPES) [2], and the SOFI Spanish Modify (SOFI$\mathrm{SM})$ [4].

As for the workload in the Latin American countries have not developed assessment tools adapted by fatigue per se for this purpose. Only two relevant reports were identified in Mexico, first one is about the development of FEPES, and second is the validation of the cutoff point for the FRSQ among Mexican workers.

\subsection{AMT environment}

Jobs where the individual performs physical and mental effort simultaneously, the worker may present symptoms of fatigue $[29,8]$. TMA operators perform this kind of work, especially where they perform loading and unloading of parts, and programming of Computer Numerical Control (CNC) machines. Physical component requires manual handling of parts with weights from $0.5 \mathrm{~kg}$ to $12 \mathrm{~kg}$, while mental component requires programming, adjustment and exchange of die in the machines. Because of this, TMA related workers might be exposed to high levels of fatigue (Mital, 1995).

Cases where has been assessed workload or fatigue in the workplace have been developed[33, 6, 13, 27]. Other studies have been conducted analyzing the work of nurses [18, 23], and others in laboratory set- ting with student volunteers $[26,1]$. Only in few cases workload and/or fatigue have been assessed in industrial environments that include some type of AMT.

\subsection{Aims}

Due to the lack of validated instruments for assessing mental workload and fatigue (physical and mental) on Mexican workers, this paper proposes to adapt and validate into Spanish language, a survey to assess workload and fatigue in industrial environments with AMT.

\section{Method}

\subsection{Identification of questionnaires and scales}

In order to identify questionnaires and scales to assess workload and fatigue were consulted scientific databases, magazines, and specialized reference books. The criteria for selecting the tools were: - Validated in Spanish and/or other languages.

- Show content and construct validity.

- Show acceptable indices of reliability in previous research.

\subsubsection{Workload assessment}

According to the above criteria, two scales were selected to assess workload.

National Aeronautics and Space Administration Task Load Index (NASA-TLX) [32] is a scale multidimensional with six subscales: mental demands, physical demands, temporary demands, effort, performance and frustration. This scale is applied in two phases. In first one, participants evaluated using a paired comparison, the relative contribution of each of the subscales presented; the second phase consists in evaluating the subscales. The values obtained are used to obtain the total workload. After performing the necessary calculations, a $0-100$ scale value is obtained, which is divided into 4 intervals. 0-25 (no shares), 26-50 (recommended shares), 51-75 (priority actions) and 76-100 (immediate action). NASA-TLX method has shown acceptable reliability indices and is easier to use than the Subjective Workload Assessment Technique (SWAT) [11]. Validity and usability of NASA-TLX have made this instrument is the most widely used for assessment of mental workload $[31,37]$. 
The questionnaire ISTAS 21 is a method for assessing the effect of psychosocial factors in the workload [34]. For the construction of this survey was used the short version that includes 38 items grouped into 6 dimensions: psychological demands (6 items), active work (10 items), job insecurity (4 items), social support (10 items), estimate to work (4 items) and double presence (4 items). This questionnaire has shown acceptable reliability indices in different work environments $[17,35]$.

\subsubsection{Fatigue assessment}

For the assessment of fatigue three questionnaires were included in the survey. The first questionnaire was the SOFI-S [18]. This is an adaptation and validation of SOFI [5] to Spanish language. This instrument was developed to assess fatigue in 5 dimensions: lack of energy, physical exertion, physical discomfort, lack of motivation and sleepiness. Each dimension includes 3 items. To calculate the values of fatigue is necessary added values obtained by the 3 items included in each dimension.

The second questionnaire was the Fatigue Assessment Scale (FAS) [13] included in this study for the assessment of total fatigue. This instrument consists of 10 items: 5 for the evaluation of physical fatigue and 5 for the evaluation of mental fatigue. Fatigue results can be obtained by dimension and globally. In both cases is necessary to add the values of items.

The third and last instrument included was the Spanish version of the questionnaire OFER-S [19], which is a translation and validation of the questionnaire OFER [28]. This version was adapted and validated for use in Mexican workers. This instrument assesses three states of fatigue: acute fatigue, chronic fatigue and intershift recovery. Each dimension is assessed with 3 items.

\subsection{Integration of the preliminary survey}

The order of the survey and the items included in each scale is shown in table 1 .

Table 1.

Survey preliminary order

\begin{tabular}{|l|l|}
\hline \multicolumn{1}{|c|}{ Questionnaire } & Items \\
\hline Demographic data & 14 \\
\hline NASA-TLX & 21 \\
\hline ISTAS 21 & 38 \\
\hline FAS & 10 \\
\hline SOFI & 15 \\
\hline OFER & 15 \\
\hline Disconfort map [7] & \\
\hline
\end{tabular}

\subsection{Measurement scales}

In order to evaluate the items included in the survey, two types of measurement scales were included. For NASA and SOFI questionnaire was included a visual analogue scale of 5 divisions that includes on the left side the terms "low / bad" and the right side "high / good". For questionnaires ISTAS 21, FAS and OFER a Likert scale of 5 points was included. Values and meaning are: 1 (never), 2 (only once), 3 (sometimes), 4 (many times) and 5 (always).

\subsection{Survey administration}

\subsubsection{Phase 1. Pilot study}

The pilot study included two groups of participants, students and industrial workers. A total 110 subjects were surveyed. The objectives of the pilot study were to calculate the indices Keiser Meyer Olkin (KMO) [30] and Cronbach alpha to test the adequacy of the sample and the reliability of the data [21] respectively. Also, know the values of workload, fatigue and the time the survey is completed by the subjects.

The implementation of the first version of the student survey was conducted within the classroom to3 groups of students. In the case of workers, implementation of the survey was conducted in the work place during scheduled breaks; all subjects included were employees of a company manufacturer of automotive harnesses.

\subsubsection{Phase 2. Application among AMT operators.}

In phase 2, the survey was administered to 121 AMT operators in a manufacturer facility. All subjects surveyed work as CNC lathes operators and currently work 12 hours shifts.

The survey was delivered to the team supervisors and they were responsible for distribution to workers. Before the workers started to answer the survey, the researchers say filling instructions to supervisors and workers. During application, the researchers monitored and supported when workers complete the survey. Data collection was conducted

\subsection{Survey validation}

In order to verify the adequacy of the sample, Kayser-Meyer-Olkin (KMO) index was calculed, which compares the magnitudes of the observed correlation coefficients between variables with the magnitudes of partial correlation coefficients between the 
variables. If the value is greater than 0.7 , the sample size is enough and is possible perform a factor analysis [30].

Reliability data and internal consistency was analyzed with Cronbach's alpha index, which indicates the proportion of variance in scores on the scale that is attributable to the real score. The index value must be greater than 0.7 to consider that the data are reliable [21].

These indices were calculated in both phases of the study, however the values considered for the validation and reliability of the survey are those obtained in the second phase.

For data analysis, software SPSS v17.0 was used.

\section{Results}

\subsection{Phase 1. Pilot study.}

The mean values, standard deviation, Cronbach's alpha and KMO indices of questionnaires and dimensions are shown in Table 4. In phase 1, Cronbach's alpha values were obtained from 0.427 to 0.887 . KMO index was obtained from 0.513 to 0.825 . In the specific case of FAS questionnaire, the lowest values in the analysis were obtained; Cronbach's alpha of 0.179 and 0.427 for mental fatigue and physical fatigue dimensions, respectively, and 0.505 for all questionnaire data. Time to complete the survey in this phase was 15-20 min.

\subsection{Phase 2. Application among AMT operators.}

\subsubsection{Modifications to the survey.}

After the results of the pilot study, two modifications were made in the survey. The first one was to eliminate FAS scale, because the Cronbach alpha values were low [21], the second modification was to move demographics section at the end of the survey [20]. The final order is shown in Table 2.

Table 2.

Final order of the survey

\begin{tabular}{|l|l|}
\hline \multicolumn{1}{|c|}{ Questionnaire } & Items \\
\hline NASA-TLX & 21 \\
\hline ISTAS 21 & 38 \\
\hline SOFI & 15 \\
\hline OFER & 15 \\
\hline Mapa de Corlet-Bishop [7] & \\
\hline Demografic data & 14 \\
\hline
\end{tabular}

\subsubsection{Participants}

In the second phase of the study, the survey was administered to $121 \mathrm{CNC}$ lathe operators in a com- pany that manufactures Constant Velocity (CV) Joints located in central Mexico. Table 3 shows demographic characteristics of the sample.

Table 3.

Demographic data of AMT operators.

\begin{tabular}{|c|c|c|c|c|c|}
\hline Variable & $\mathrm{n}$ & $\%$ & Variable & $\mathrm{n}$ & $\%$ \\
\hline Age & & & $\begin{array}{l}\text { Time in the } \\
\text { company }\end{array}$ & & \\
\hline$<20$ & 2 & 2 & $<1$ & 13 & 11 \\
\hline $21-30$ & 77 & 71 & $1-3$ & 32 & 28 \\
\hline $31-40$ & 25 & 23 & $3-6$ & 53 & 46 \\
\hline $41-50$ & 4 & 4 & $6-9$ & 3 & 3 \\
\hline$>51$ & 1 & 1 & $>20$ & 15 & 13 \\
\hline Height $(\mathrm{cm})$ & & & Time & & \\
\hline$<160$ & 5 & 4 & $<1$ & 24 & 24 \\
\hline $160-165$ & 36 & 32 & $1-3$ & 30 & 30 \\
\hline $166-170$ & 33 & 28 & $3-6$ & 40 & 40 \\
\hline $171-175$ & 20 & 17 & $6-9$ & 1 & 1 \\
\hline $176-180$ & 14 & 12 & $>20$ & 4 & 4 \\
\hline \multirow[t]{2}{*}{$>180$} & 8 & 7 & & & \\
\hline & & & Position & & \\
\hline Weight $(\mathrm{Kg})$ & & & Operator & 116 & 95 \\
\hline$<60$ & 11 & 9 & $\begin{array}{l}\text { Grupolid- } \\
\text { er/operator }\end{array}$ & 6 & 5 \\
\hline $61-70$ & 31 & 26 & & & \\
\hline $71-80$ & 37 & 31 & Marital status & & \\
\hline $81-90$ & 23 & 19 & Single & 29 & 27 \\
\hline $91-100$ & 13 & 11 & Married & 78 & 73 \\
\hline$>100$ & 3 & 3 & $\begin{array}{ll}\begin{array}{l}\text { Divorsed } \\
\text { separated }\end{array} & \text { o }\end{array}$ & 0 & 0 \\
\hline $\begin{array}{l}\text { Number of } \\
\text { dependents }\end{array}$ & & & $\begin{array}{l}\text { Hours of sleep } \\
\text { per night }\end{array}$ & & \\
\hline 0 & 14 & 13 & $<5$ & 3 & 3 \\
\hline $1-2$ & 55 & 49 & $5-6$ & 37 & 33 \\
\hline $3-4$ & 36 & 32 & $6-7$ & 39 & 35 \\
\hline \multirow[t]{3}{*}{$>5$} & 7 & 6 & $7-8$ & 24 & 22 \\
\hline & & & $8-9$ & 6 & 5 \\
\hline & & & $>9$ & 2 & 2 \\
\hline \multicolumn{6}{|l|}{$\begin{array}{l}\text { Highest educa- } \\
\text { tional degree }\end{array}$} \\
\hline Elementary & 0 & 0 & & & \\
\hline Secondary & 9 & 7.6 & & & \\
\hline Preparatory & 43 & 36.7 & & & \\
\hline Technical & 65 & 55.5 & & & \\
\hline
\end{tabular}

\subsubsection{Workload levels}

Levels of workload obtained with NASA-TLX questionnaire in the first phase of the study show no important differences. Values of 3.13 to 3.85 for all variables except the variable physical effort that obtained 2.12 points. In the case of AMT operators, the variable with the highest average value was performance, obtaining 4.23 and the lowest value was frustration with 2.81 . 
Results of questionnaire ISTAS 21 shown important similarities. In both phases of the study the dimension social support and leadership obtained the highest score, 35.5 and 35.41 for phase 1 and phase 2, respectively. Dimensions job insecurity and double presence obtained the lowest values, in first phase obtained 11.2 and 11.7 points, respectively; in second phase obtained 8.17 and 8.65 points, respectively.

\subsubsection{Fatigue levels}

Fatigue levels obtained with SOFI-S questionnaire shown important differences in both studies. In the first phase, sleepiness dimension obtained the highest value with 8.74 . In contrast, in the second phase where AMT operators were surveyed, lack of energy dimension obtained the highest value with $\bullet .76$.
For the OFER questionnaire, the three dimensions considered by the instrument obtained similar values with no apparent differences in the two study phases. Chronic fatigue dimension obtained the highest values with 15.43 and 14.46 for the first and second phases, respectively, followed by the intershift recovery dimension with 12.9 and 13.13 for the first and second phases, respectively, and dimension acute fatigue with values of 10.35 and 10.19 for the first and second phase, respectively.

Table 4.

Mean, Std. deviation, KMO and Cronbach alpha obtained in two phases

\begin{tabular}{|c|c|c|c|c|c|c|c|c|c|c|}
\hline \multicolumn{6}{|c|}{ Phase 1. Pilot study $(n=110)$} & \multicolumn{5}{|c|}{$\begin{array}{l}\text { Phase 2. Administration among AMT operators } \\
\qquad(\mathrm{n}=121)\end{array}$} \\
\hline $\begin{array}{l}\text { Question- } \\
\text { naire }\end{array}$ & Dimension & Mean & $\begin{array}{l}\text { Desv } \\
\text { Std. }\end{array}$ & KMO & Alpha & $\begin{array}{l}\text { Ques- } \\
\text { tionnaire }\end{array}$ & Mean & $\begin{array}{l}\text { Desv } \\
\text { Std. }\end{array}$ & KMO & Alpha \\
\hline \multirow{6}{*}{$\begin{array}{l}\text { NASA- } \\
\text { TLX } \\
\alpha: 0.791 \text {, } \\
\text { KMO: } \\
0.801\end{array}$} & Mental demands & 3.71 & 0.949 & N/A & N/A & \multirow{6}{*}{$\begin{array}{l}\text { NASA- } \\
\text { TLX } \\
\alpha: 0.583 \text {, } \\
\text { KMO: } \\
0.664\end{array}$} & 3.61 & 0.86 & N/A & N/A \\
\hline & Physical demands & 2.12 & 1.07 & $\mathrm{~N} / \mathrm{A}$ & $\mathrm{N} / \mathrm{A}$ & & 3.57 & 1.03 & N/A & N/A \\
\hline & Temporal demands & 3.34 & 0.94 & N/A & N/A & & 3.26 & 0.81 & N/A & N/A \\
\hline & Effort & 3.75 & 0.85 & N/A & N/A & & 3.88 & 0.77 & N/A & N/A \\
\hline & Performance & 3.85 & 0.86 & N/A & N/A & & 4.23 & 0.68 & N/A & N/A \\
\hline & Frustration & 3.13 & 1.16 & $\mathrm{~N} / \mathrm{A}$ & $\mathrm{N} / \mathrm{A}$ & & 2.81 & 1.00 & N/A & N/A \\
\hline \multirow{6}{*}{$\begin{array}{l}\text { ISTAS } \\
\alpha: 0.860 \text {, } \\
\text { KMO: } \\
0.712 .\end{array}$} & Psychological demands & 16.9 & 3.48 & 0.728 & 0.733 & \multirow{6}{*}{$\begin{array}{l}\text { ISTAS } \\
\alpha: 0.702, \\
\text { KMO: } \\
0.753 .\end{array}$} & 15.33 & 3.69 & 0.711 & 0.654 \\
\hline & Active work & 35 & 6.55 & 0.825 & 0.813 & & 32.8 & 4.71 & 0.628 & 0.6 \\
\hline & Job insecurity & 11.2 & 4.09 & 0.548 & 0.521 & & 8.17 & 3.56 & 0.681 & 0.641 \\
\hline & Social suport & 35.5 & 6.09 & 0.738 & 0.759 & & 35.41 & 6.38 & 0.755 & 0.8 \\
\hline & Estimate to work & 13.16 & 2.93 & 0.760 & 0.764 & & 11.82 & 3.65 & 0.768 & 0.846 \\
\hline & Double presence & 11.7 & 3.24 & 0.564 & 0.485 & & 8.65 & 2.54 & 0.601 & 0.591 \\
\hline \multirow{5}{*}{$\begin{array}{l}\text { SOFI-S } \\
\alpha: 0.845, \\
\text { KMO: } \\
0.756 .\end{array}$} & Lack of energy & 6.54 & 2.56 & 0.728 & 0.836 & \multirow{5}{*}{$\begin{array}{l}\text { SOFI-S } \\
\alpha: \\
0.881, \\
\text { KMO: } \\
0.813 .\end{array}$} & 7.76 & 2.29 & 0.700 & 0.827 \\
\hline & Physical exertion & 6.59 & 2.73 & 0.513 & 0.433 & & 6.61 & 2.00 & 0.552 & 0.558 \\
\hline & Physical discomfort & 6.18 & 3 & 0.625 & 0.773 & & 6.18 & 2.24 & 0.652 & 0.742 \\
\hline & Lack of motivation & 6.28 & 2.31 & 0.731 & 0.887 & & 1.99 & 0.72 & 0.619 & 0.754 \\
\hline & Sleepiness & 8.74 & 2.85 & 0.664 & 0.794 & & 5.677 & 2.24 & 0.708 & 0.793 \\
\hline \multirow{2}{*}{$\begin{array}{l}\text { FAS } \\
\alpha: 0.505 \\
\text { KMO:0.74 } \\
6\end{array}$} & Physical fatigue & 14.30 & 3.11 & 0.596 & 0.427 & \multirow[t]{2}{*}{ FAS } & N/A & $\mathrm{N} / \mathrm{A}$ & N/A & N/A \\
\hline & Mental fatigue & 13.54 & 3.05 & 0.632 & 0.179 & & $\mathrm{~N} / \mathrm{A}$ & N/A & N/A & N/A \\
\hline \multirow{3}{*}{$\begin{array}{l}\text { OFER } \\
\alpha: 0 ., 724 \\
\text { KMO: } \\
0.813 .\end{array}$} & Acute fatigue & 10.35 & 3.76 & 0.779 & 0.786 & \multirow{3}{*}{$\begin{array}{l}\text { OFER } \\
\alpha: 0.678 \text {, } \\
\text { KMO: } \\
0.803\end{array}$} & 10.19 & 3.45 & 0.768 & 0.677 \\
\hline & Chronic fatigue & 15.43 & 2.91 & 0.771 & 0.427 & & 14.46 & 2.62 & 0.725 & 0.695 \\
\hline & Intershift recovery & 12.9 & 2.52 & 0.561 & 0.700 & & 13.13 & 2.15 & 0.689 & 0.751 \\
\hline \multicolumn{6}{|c|}{$\alpha: 0.842 ;$ KMO: $0.75 ; 84$ items. } & \multicolumn{5}{|c|}{ Alfa: $0.806 ;$ KMO: $0.617 ; 74$ items. } \\
\hline \multicolumn{5}{|c|}{ Time to complete the survey: $15-20 \mathrm{~min}$. } & & \multicolumn{5}{|c|}{ Time to complete the survey: $20-15 \mathrm{~min}$. } \\
\hline
\end{tabular}

\subsubsection{Reliability índices}

KMO index ranged from 0.552 to 0.813 and the Cronbach alpha index were 0.558 to 0.881 . All calculated values can be seen in Table 4.

\section{Discussion}

In the second phase of the study, Cronbach's alpha index obtained for the NASA-TLX questionnaire decreased rom 0.791 to 0.801 , just as the KMO index decreased from 0.583 to 0.664 . 
In the case of the questionnaire ISTAS 21, only for active work dimension indices Cronbach alpha and $\mathrm{KMO}$ decreased from 0.825 and 0.813 to 0.628 and 0.6 , respectively.

For the SOFI-S questionnaire, the values of Cronbach's alpha indices and KMO were higher than 0.7 in both phases of the study, this confirms that the application of this method for fatigue assessment is reliable. However, physical effort dimension obtained values lower than 0.6 , the lowest values in this questionnaire. This situation coincides with the values obtained in the developing of SOFI questionnaire [5] in the validation of the SOFI-S [18], and when nurses are surveyed [23].

Finally, for OFER questionnaire, two values below 0.7 were obtained, chronic fatigue dimension with 0.427 for Cronbach's alpha and acute fatigue dimension with $0.561 \mathrm{KMO}$ index. The other values were higher than 0.7 or very close to it.

\section{Conclusion}

Although some values were below 0.7 for Cronbach alpha and KMO, indices of reliability are consistent with the values of the sample adequacy, however is necessary to increase the sample size, recalculate these values and evaluate whether it improves the survey reliability.

Values obtained for the KMO indices and Cronbach alpha improved in the second phase of the study, with the exception of the active work dimension of the questionnaire ISTAS 21, lack of motivation dimension of SOFI-S questionnaire, and the overall value of the questionnaire NASA-TLX where rates declined. After the methodology and data analysis conducted, has been validated the first version of the survey for the assessment of workload and fatigue in AMT operators in Mexico.

\section{References}

[1] A. DiDomenico A. y Nussbaum M. Interactive efects of physical and mental workload on subjective worloadassessemnt. International Journal of Industrial Ergonomics (2008) 38. 977 983.

[2] A. Juarez-Garcia. The fatigue-energy dimension as presenteeism indicator: validity of a proposed scale in Mexican workers. Revista ciencia y trabajo. Año 9, 24, (2007), 55-60.

[3] A. Mital. The role of ergonomics in designing for manufacturability and humans in general in advanced manufacturing technology: Preparing the American workforce for global competition beyond the year 2000. International Journal of Industrial Ergonomics. 1995, 129-135.
[4] C. M. Sebastian, G. V. Idoate, L. M. Llano, E. F. Almanzor. SOFI-SM: cuestionariopara el análisis de la fatigalaboralfísica, mental y psíquica. Revista digital de seguridad y salud en el trabajo(2008) N. 2. Pág. 1-22.

[5] E. Ahsberg E., Gamberale F, Kjellberg A. Perceived quality of fatigue during different occupational tasks Development of a questionnaire. International Journal of Industrial Ergonomics, 20 (1997), 121-135

[6] E. Diaz, S. Rubio, J. M. García and L. Luceño. Psuchometric study os NASA-TLX Mental workload index in a sample of spansh workers. Revista de psicología del trabajo y d elasorganizaciones. (2010) Vol. 26-3. 191-199.

[7] E. N. Corlett, and R. P. Bishop. A technique for assessing postural discomfort. Ergonomics, Vol. 19(2), 175-182. 1976.

[8] F. Farrer, F., Minaya, G., Escalante, J., Ruiz, M. Manual de ergonomía. FundaciónMapfre. (1995).

[9] F. Guelaud, M. N. Beauchesne, J. Gautrat, G. \&Roustang. Pour uneanalyse des conditions du travail ouvrierdansl'entreprise. Paris: A. Collin. (1977).

[10]G. Borg. Psychophysical bases of perceived exertion. Medicine and science in sport and exercise (1982). 14, 377-381.

[11]G.B. Reid and T.E. Nygren. The subjective workload assessment technique: A scaling procedure for measuring mental workload. (1988). Human mental workload(pp. 185-218). Amsterdam: Elsevier.

[12] G. G. Rolo , C. D. Díaz and F. E. Hernández.Desarrollo de una Escala Subjetiva de Carga Mental de Trabajo (ESCAM). Revista de Psicología del Trabajo y de las Organizaciones. Vol. 25, n. ${ }^{\circ}$ 1. (2009), 29-37.

[13]H. Huang, D. Geng. Study of Industrial Fatigue of Workers in theMachineryManufacturer. International ErgonomicsAssociationConference, Beijing, (2009).

[14]H. J. Michielsen; J. De Vries,G. L. Van Heck; F. J. R. Van de Vijver and K. Sijtsma Examination of the Dimensionality of Fatigue: The Construction of the Fatigue Assessment Scale (FAS). European Journal of Psychological Assessment, Vol 20(1), (2004), 39-48.

[15]H. S. Jung Establishment of overall workload assessment technique for various tasks and workplaces. International Journal of Industrial Ergonomics 28 (2001) 341-353.

[16]H. R. Jex. Measuring mental worikload: problems, progress, and promises. In P. a. Hancock and N Meshkati (Eds). Human Mental Workload. Amsterdan: Elsevier Science (1988).

[17]H. Yoshitake. Three characteristic patterns of subjective fatigue symptoms. Ergonomics 21, (1978). 231-233.

[18]I. Dalmau. Evaluacion de la carga mental en tareas de control: técnicas subjetivas y medidas de exigencia. Tesis doctoral. Barcelona. Universidad Politecnica de Cataluña, 2007.

[19] J. L. González, J. B. Moreno, H. A. Garrosa, L. A. López. Spanish version of the Swedish Occupational Fatigue Inventory (SOFI): Factorial replication, reliability and validity. International Journal of Industrial Ergonomics 35, (2005), 737746.

[20]J. L. Hernandez, J. L García, J.J. Flores and N. E. Vazquez. Versión en Español de la escala de recuperaciónporfatiga. CongresoINternacional de Investigación Academia Journals.com (2011). 218-222.

[21] J. M. Huerta. Procecimiento para redactar y validar los cuestionarios para los estudios de investigación y evaluación. Universidad de Puerto Rico, Recinto Universitario de Mayagüez (2005).

[22]J. NunallyTeoria psicométrica. Mexico. DF. Mc Graw Hill. (1995) 254, 600-603.

[23]K. Kroemer, K., Kroemer, H., and Kroemer-Elbert, K. Ergonomics: how to design for ease \& efficiency. Englewood Cliffs, NJ: Prentice Hall. (1994). 
[24]L. M. Barker. Measuring and modeling the effects of fatigue on performance: Specific application to the nursing profession.(2009). PhD Disertation. University of Virginia. United States.

[25]M. A. Vidulich\& P.S Sang. Assessing subjective Workload Assessment.: A comparison of SWAT and the NASA-Bipolar Methods. In proceedings of the Human Factors Society. $29^{\text {th }}$ Annual Meeting Santa Monica, CA: Human Factors Society. ((1985) pp. 71-75)

[26] M. L. Sebastián, V. M. Idoate, L. M. Llano and F. E. Almanzor. SOFI-SM: cuestionario para el análisis de la fatiga laboral física, mental y psíquica. Revista digital de seguridad y salud en el trabajo N. 2. (2008), 1-22.

[27]M. A. Recarte, E. Perez, A. Conchillo, L. M. Nunes. Mental Workload ans Visual Impairment: Differences between Puñil, Blink, and Subjective Rating. The Spanish Journal of Psychology (2008) 11. 371-386.

[28] N. Sato, T. Kamada, S. Miyake, J Akatsu, M. Kumashiro, Y. Kume. Subjective workload in Type A women. International JOurnla of Industrial Ergonomics (1999). 24. 331-336.

[29]P. C. Winwood, A. H. Winefield, D. Dawson and K. Lushington, . Development and validation of a scale to measure workrelated fatigue and recovery: The Occupational Fatigue Exhaustion/Recovery Scale (OFER). Journal of Occupational and Environmental Medicine, 47, (2005), 594-606.

[30] P. Mondelo, E. Gregori E. La ergonomía en la ingeniería de sistemas. Isdefe (1996)

[31] R. Alvarez. Estadisticamultivariante y no paramétrica con SPSS. Aqplicación a las ciencias de la salud. Madrid: Díaz de santos. (1995). 243-244.

[32] S. G. Charlton. Selectingmeasuresfor human factores test. In S. G. Charlton \& T. G: O'Brien (Eds). Handbook of human factorstesting and evaluation. Mahwah: Lawrence
ErlbaumAssociates

[33] S. G. Hart and L. E. Staveland, Development of NASA-TLX (Task Load Index): Results of empirical and theoretical research. In P.A. Hancock \& N. Meshkati (Eds. Human mental workload Amsterdam: North-Holland, (1988), 139-183.

[34] S. Miyake. Multivartiateworkloadevaluationcombiningphysiological and subjegivemeasures. International JOurnal of Psychopshysiology. (2001) 40. 233-238.

[35] S. Moncada, C. Llorens y T. S. Kristensen. Evaluación del Riesgo psicosocial: el método ISTAS-21 (COPSOQ) Instituto Sindical del Trabajo, Ambiente y Salud, ISTAS, (2003). Barcelona.

[36] S. Moncada, C Llorens, A. Font, A. Galtes and A. Navarro. Exposición a riesgos psicosociales entre la población asalariada en España, valores de referencia de las 21 dimensiones del cuestionario copsoq istas 21 , Revesp salud pública (2008). 82. 667-675

[37] T. Barrientos-Gutiérrez, S. Martínez-Alcántara, I. MéndezRamírez. Construct validity, reliability, and cutoff point of the Subjective Symptoms of Fatigue Test in Mexican workers. Revista Salud Publica de México 46, (2004), 516-523.

[38] T. Rutledge, E. Stucky, A. Dollarhide, M. Shively, S. Jain, T. Wolfson, M. B. Matthew, T. Dresselhaus. A real-time assessment of work stress in physicians nurses. Healthpsychology. Vol. 28-2 (2009). 194-200.

[39] T. S. Kristensen. Metodo ISTAS 21. Instituto Sindical de Trabajo, Ambiente y Salud de España (ISTAS). 2002.

[40] W. Wierwille, \& J. G. Casalli. A Validated Rating Scale for Global Mental Workload Measurement Application. In proceedings of the Human Factors Society $27^{\text {th }}$ Annual Meeting. Santa Monica, CA: Human Factors Society. (1983). 129-133. 